\title{
MicroRNA 1290
}

National Cancer Institute

\section{Source}

National Cancer Institute. MicroRNA 1290. NCI Thesaurus. Code C157567.

A 19 ribonucleotide sequence that is a final product of the processing of MIR1290 pre-

miRNA. This oligonucleotide may be involved in the regulation of gene expression in various cancers. 